\title{
The protective effects of exogenous spermine on renal ischemia-reperfusion injury in rats
}

\author{
Bo Yan ${ }^{1 \#}$, Shao-Ju Min ${ }^{2 \#}$, Bin $\mathrm{Xu}^{1}$, Cheng Zhang ${ }^{1}$, Jun Pei $^{3}$, Wei Zhang ${ }^{1}$, Guang-Heng Luo ${ }^{1}$ \\ ${ }^{1}$ Department of Urology, Guizhou Provincial People's Hospital, Medical College of Guizhou University, Guiyang, China; ${ }^{2}$ Department of Clinical \\ Laboratory, The Affiliated Hospital of Guizhou Medical University, Guiyang, China; ${ }^{3}$ Surgery Specialty, Faculty of Graduate Studies, Guizhou \\ Medical University, Guiyang, China \\ Contributions: (I) Conception and design: B Yan; (II) Administrative support: GH Luo; (III) Provision of study materials or patients: SJ Min; \\ (IV) Collection and assembly of data: B Xu; (V) Data analysis and interpretation: J Pei; (VI) Manuscript writing: All authors; (VII) Final approval of \\ manuscript: All authors. \\ \#These authors contributed equally to this work. \\ Correspondence to: Guang-Heng Luo. Department of Urology, Guizhou Provincial People's Hospital, Medical College of Guizhou University, \\ Guiyang, China. Email: luoguangheng1975@126.com.
}

Background: To investigate the protective effects of exogenous spermine on renal ischemia-reperfusion injury in rats.

Methods: (I) Different doses of spermine were injected into rats to determine the safe dose on the kidneys. Kidney toxicity was assessed by hematoxylin and eosin (HE) staining of kidney tissue and enzyme-linked immunosorbent assay (ELISA) detection of neutrophil gelatinase-associated lipocalin (NGAL) and kidney injury molecule 1 (KIM-1) in the venous blood. (II) A rat model of renal ischemia-reperfusion injury was established. Different doses of spermine were injected into the rats through the tail vein 30 minutes before and 3 days after the establishment of the model. Blood samples and kidney tissues were collected and renal injury was assessed via HE staining of the renal tissue, detection of apoptosis using the TUNEL assay, and detection of NGAL and KIM-1 in blood samples using ELISA. (III) Human HK-2 renal tubular epithelial cells were cultured under hypoxia/reoxygenation conditions. To evaluate the protective effects of spermine, apoptosis was assessed by flow cytometry and TUNEL assay. The mechanisms underlying the effects of spermine were studied using Western blot analyses.

Results: At spermine concentrations below $200 \mu \mathrm{M}(2 \mathrm{~mL} / \mathrm{kg}$ body weight), no significant damage to the kidney was observed by HE staining, and there was no significant difference in NGAL and KIM-1 levels between rats treated with spermine and control rats $(\mathrm{P}<0.05)$. At spermine doses below $200 \mu \mathrm{M}, \mathrm{HE}$ staining showed that the degree of renal ischemia-reperfusion injury was gradually alleviated with increasing doses of spermine. TUNEL assays demonstrated that spermine reduced the apoptosis of renal tissue, and increasing doses of spermine gradually decreased the levels of NGAL and KIM-1 in the blood compared with the control group $(\mathrm{P}<0.05)$. Western blot analysis revealed that spermine increased the expression of pro-caspase9, phosphorylated protein kinase B (p-Akt), hypoxia-inducible factor 1 alpha (HIF-1 $\alpha), B$ cell lymphoma 2 (Bcl-2), and $\mathrm{Bcl} 2$ interacting protein 3 (BNIP3), and decreased the expression of cleaved caspase-3, Bax and cytochrome $\mathrm{C}$ compared to control cells.

Conclusions: Exogenous spermine exerted a protective effect on renal ischemia-reperfusion injury in rats by inhibiting the apoptosis of renal tubular epithelial cells.

Keywords: Spermine; ischemia-reperfusion; renal; Akt/mTOR; HIF-1 $\alpha$

Submitted Jan 31, 2021. Accepted for publication May 13, 2021.

doi: $10.21037 /$ tau-21-280

View this article at: http://dx.doi.org/10.21037/tau-21-280 


\section{Introduction}

Ischemia-reperfusion injury (IRI) is a pathological state in which a return of blood supply to an ischemic organ results in aggravated dysfunction and structural damage to that organ $(1,2)$. The kidney is one such organ that is sensitive to IRI because of its special tissue function and structure. At present, there are no specific drugs for the treatment of renal ischemia-reperfusion injury. There are many signaling pathways involved in the pathogenesis of renal ischemia-reperfusion injury. It is generally believed that $\mathrm{Ca}^{2+}$ overload, oxygen free radical secretion, cell adhesion molecule activation, chemokine participation, leukocyte interaction, and other interactions lead to tissue inflammation, necrosis, apoptosis, and eventually organ failure (3-5).

Clinically, renal IRI often occurs in the process of kidney transplantation, partial nephrectomy, and heart surgery. The latter is a main cause of acute kidney injury, and the mortality rate accounts for $20 \%$ of hospitalized patients (6). Therefore, effectively preventing renal IRI and reducing mortality has become an important clinical goal.

The pathophysiology of renal IRI is complex and regulated by many signaling factors. Renal tubular epithelial cells (TEC) play a key role in the process of IRI. They are both victims and implementers of IRI (7). Three key signaling factors related to IRI have been identified in renal tubular epithelial cells, namely toll-like receptors (TLRs), sphingosine-1-phosphate (S1P) receptors, and hypoxia induced factors (HIFs) (8-10). The TEC signaling pathway has significant intracellular and intercellular effects, making it a powerful target for the treatment of IRI. Farrar (11) and others have shown that anti-TLR2 antibodies can improve the function of transplanted kidneys in an allogeneic transplantation model. OPN-305 is another anti-TLR2 antibody which is in phase II clinical trials and can significantly reduce the release of IL-6 and improve the delayed recovery of renal function in renal transplant patients. To date, there have been no successful clinical trials targeting S1P receptors and HIFs $(7,12)$. Other studies have reported that thrombomodulin can reduce the inflammatory injury induced by hepatic ischemia-reperfusion injury in a TLR4-dependent manner. Due to the complexity of the pathological process of renal IRI, blocking a specific target or signal transduction pathway with drugs does not provide complete protection, and the clinical outcome is not satisfactory (13).

Polyamines were first discovered in semen by
Leeuwenhoek in 1678 (14). Vertebrates contain two kinds of polyamines, spermine and spermidine, and their precursor putrescine. Polyamines are the main cations in cells and are mainly bound to anionic molecules such as DNA and RNA (15). They play an important role in cell physiology and are involved in regulating cell growth and proliferation, controlling the biosynthesis of nucleic acids and proteins, regulating ion channel activity and kinase activity, apoptosis, and immune responses (16-20). They also have effective antioxidant activity at physiological concentrations, which can prevent damage to cell membranes and DNA (19). A study published in Nature Medicine in 2016 showed that the median life span of mice supplemented with spermine or spermidine was significantly longer than that of the control mice or mice supplemented with putrescine (21). The results demonstrated that oral administration of natural polyamines exerted cardioprotective effects on aged mice, reduced myocardial hypertrophy, and maintained diastolic function. It also enhanced autophagy, mitosis and mitochondrial respiration, and improved the mechanical elasticity of myocardial cells in vivo. However, Bonneau et al. (22) observed cell death by spermine oxidationmediated necrosis rather than apoptosis in mouse leukemia cell lines. Although there is no doubt that spermine is involved in the process of cell death, its role in apoptosis is still controversial (23). Most reports have shown that spermine has a protective effect on cell apoptosis, but some studies have suggested that spermine may prevent or activate cell apoptosis depending on the cell type. Indeed, some reports have suggested that increased concentrations of spermine may lead to apoptotic cell death or malignant transformations (16).

The Chinese scholar Professor Xu and colleagues (24) were the first to demonstrate, through many years of research, that spermine levels in tissues do not increase, but rather decrease significantly during ischemiareperfusion, suggesting that the metabolic homeostasis of polyamine is crucial. They showed that spermine is a "double-edged sword" with a dual regulatory effect on calcium sensitive receptors. High doses of spermine increased the levels of free calcium in myocardial cells in a dose-dependent manner. It also resulted in calcium explosion and necrosis of acute isolated rat cardiomyocytes and cultured neonatal rat cardiomyocytes. In contrast, low doses of exogenous spermine significantly reduced myocardial reperfusion injury, intracellular calcium overload, antioxidation, oxygen free radical injury, and apoptosis. 
To date, there have been no reports in the literature examining the use of exogenous spermine in renal IRI. This current study identified the doses of spermine that could exert a protective effect on renal ischemia-reperfusion injury in rats without any nephrotoxic effects. The mechanisms of action were investigated. Furthermore, the effects of spermine on the apoptosis of renal tubular epithelial cells were assessed in vitro.

We present the following article in accordance with the ARRIVE reporting checklist (available at http://dx.doi. org/10.21037/tau-21-280).

\section{Methods}

\section{Animal handling and anesthesia}

Male Sprague Dawley rats (8 weeks old) were purchased from Southern Medical University and housed under constant temperature and humidity with free access to food and tap water. Experiments were performed under a project license (NO.: 2020-065) granted by ethics board of Guizhou Provincial People's Hospital, in compliance with China national or institutional guidelines for the care and use of animals. After one week of adaptive feeding, the dose range of spermine that is safe for rat kidneys were established and its protective effects on renal IRI were studied. During the operation, rats were anesthetized with $1.5-2 \%$ isoflurane (Sigma Aldrich, Y0000858), and buprenorphine $(0.05 \mathrm{mg} / \mathrm{kg}$, Sigma Aldrich, B-044) was injected subcutaneously prior to abdominal incision.

\section{Exploration of the safe concentration range of spermine}

To explore the safe concentration range of spermine in rat kidneys, 50,100,150, 200, 250, and $300 \mu \mathrm{M}$ of spermine (Sigma, S4264) were assessed, and normal saline was used as a control. The principle of randomized grouping was adopted, and five rats in each group were injected intravenously ( $2 \mathrm{~mL} / \mathrm{kg}$ body weight). After 72 hours, the rats were anesthetized, the kidneys were harvested by laparotomy, and blood samples from the inferior vena cava were collected into Eppendorf tubes without anticoagulant. After standing at $4{ }^{\circ} \mathrm{C}$ for 2 hours, samples were centrifuged at $1,500 \times \mathrm{g}$ for 10 minutes, and the supernatant was cryopreserved. The renal tissue was fixed with $4 \%$ paraformaldehyde for 24 hours, and the sections were embedded according to the conventional method (25).

\section{Establishing the renal ischemia-reperfusion injury model}

Five rats in each group were intraperitoneally injected with 100 or $150 \mu \mathrm{M}$ spermine ( $2 \mathrm{~mL} / \mathrm{kg}$ body weight), and the principle of randomized grouping was adopted. After 30 minutes, unilateral renal ischemia-reperfusion was established by clamping the left renal artery with micro spring forceps for 45 minutes. During the whole operation, the body temperature of the mice were maintained at $37 \pm 0.5^{\circ} \mathrm{C}$ using heating lamps and heating pads with automatic temperature monitoring. Post-operatively, the rats were fed the same diet as before the operation. After the operation, spermine was injected into the tail vein once a day for 3 days until the end of the experiment. In the sham operation group, the kidney was exposed without clamping the left renal artery with micro spring forceps.

\section{Collection of specimens}

Blood was collected from the inferior vena cava of rats following anesthesia with isoflurane. Whole blood was anticoagulated with $2 \mathrm{mMethylenediaminetetraacetic}$ acid (EDTA; Sigma Aldrich, Stockholm, Sweden) and immediately centrifuged at $4^{\circ} \mathrm{C}$ for 7 minutes at $1,500 \times g$. Plasma was collected and stored at $-80^{\circ} \mathrm{C}$. The heart was perfused with $35 \mathrm{~mL}$ cold phosphate buffered saline (PBS). After transverse cutting, the kidneys were fixed in $4 \%$ PBS buffered zinc formaldehyde (Histolab Products AB, Gothenburg, Sweden) at $4{ }^{\circ} \mathrm{C}$ for 24 hours and routinely embedded in paraffin and sectioned. The remaining renal tissue was rapidly frozen in dry ice and stored at $-80^{\circ} \mathrm{C}$.

\section{Hematoxylin and Eosin (HE) staining}

Varying doses of spermine were injected into the tail veins of rats. After 24 hours, rats in each group were anesthetized $(\mathrm{n}=5)$ and reperfused with $200 \mathrm{~mL}$ of normal saline followed by $200 \mathrm{~mL}$ of $4 \%$ formaldehyde to the aorta. The animals were sacrificed, and the kidneys were harvested and embedded in paraffin. Samples were cut into $5 \mu \mathrm{m}$ thick sections and HE staining was performed by conventional methods (26). The degree of kidney injury was observed under a light microscope (Olympus).

\section{Enzyme-linked immunosorbent assay (ELISA) analysis}

The levels of neutrophil gelatinase-associated lipocalin (NGAL) and kidney injury molecule 1 (KIM-1) in rat serum were detected using the Lipocalin-2 (LCN2/NGAL) 
Rat ELISA Kit (Invitrogen, Cat.\# ERLCN2) and the Rat KIM-1 (TIM-1/HAVCR) Quantitative Detection ELISA Kit (R\&D, cat. \# RKM100) according to the manufacturer's instructions.

\section{Periodic acid Schiff (PAS) staining}

The PAS staining kit (Abcam, ab150680) was used for histological analysis of the kidney sections. Slides containing kidney samples were dewaxed and hydrated in distilled water, immersed in periodate solution for 10 minutes followed by four rinses with distilled water. The slides were then immersed in Schiff's solution for 30 minutes and washed with hot tap water followed by distilled water. The slides were stained in hematoxylin for 2-3 minutes and washed in tap water for 2-3 minutes. After treatment with the bluing agent for 30 seconds, slides were washed again with distilled water, dehydrated using a gradient ethanol, and sealed with synthetic resin.

\section{TUNEL (terminal deoxynucleotidyl transferase dUTP nick end labeling) analysis}

TUNEL was used to detect renal tissue apoptosis using the colorimetric cell apoptosis detection system (Promega, cat. \# 7130). The slides were washed twice in xylene to remove the paraffin, soaked in $100 \%$ ethanol for 5 minutes, and then rehydrated in step concentration ethanol (100\%, $95 \%, 85 \%, 70 \%$, and $50 \%)$. The slides were treated in $4 \%$ paraformaldehyde for 15 minutes, followed by $100 \mu \mathrm{L}$ protease K solution $(20 \mu \mathrm{g} / \mathrm{mL})$ for penetration. The slides were repeatedly fixed in $4 \%$ paraformaldehyde for 5 minutes, and $100 \mu \mathrm{L}$ equilibrium buffer was added for 5-10 minutes. Subsequently, $100 \mu \mathrm{L}$ terminal deoxynucleotidyl transferase (TDT) reaction mixture was added to the tissue sections and a plastic cover glass was applied to ensure a uniform distribution of the mixture. The slides were incubated in a humidified chamber at $37^{\circ} \mathrm{C}$ for 60 minutes. The plastic covers were then removed and the slides were immersed in $2 \times$ saline-sodium citrate (SSC) buffer for 15 minutes to stop the reaction. The slides were then sealed in $0.3 \%$ hydrogen peroxide for 3-5 minutes. Samples were incubated with $100 \mu \mathrm{L}$ streptavidin horseradish peroxidase (HRP; diluted 1:500 in PBS) for 30 minutes. Staining with $100 \mu \mathrm{L}$ DAB (3,3'-diaminobenzidine) resulted in a light brown background. Five non-overlapping visual fields were randomly selected in each section and observed under light microscopy. The positive cells were counted and expressed as mean \pm standard deviation. The apoptotic cell index (apoptotic cells/total cells) was used as an indicator of the degree of apoptosis.

\section{Cell culture and treatment}

The HK-2 human renal tubular epithelial cell line was purchased from American Type Culture Collection (ATCC). The cells were cultured at $37{ }^{\circ} \mathrm{C}$ and $5 \% \mathrm{CO}_{2}$ in Dulbecco's Modified Eagle Medium (DMEM)/F-12 medium (Gibco, Cat.\# 11320082) supplemented with $10 \%$ fetal bovine serum (FBS; Gibco, Cat.\# 10100147) and $1 \%$ double antibody (Gibco, Cat.\# 15240062). Cells were harvested with trypsin $(0.05 \%) /$ EDTA. The in vitro hypoxia-reoxygenation model was established as previously described (27). Briefly, high glucose DMEM medium was replaced by glucose-free DMEM to simulate ischemia. The HK-2 cells were incubated in glucose-free DMEM in an anaerobic incubator at $37{ }^{\circ} \mathrm{C}$ for 24 hours. In this incubator, the air was removed by a pump and replaced with $5 \%$ $\mathrm{H}_{2}$ and $95 \% \mathrm{~N}_{2}$. Subsequently, the hypoxic medium was removed and replaced with high glucose medium, and cells were incubated in a conventional incubator to simulate reperfusion. The cells were divided into the following four treatment groups: a hypoxia-reoxygenation (H/R) group, two $H / R+$ spermine groups $(10$ and $50 \mu M)$, and a control group. Spermine was added when the cells were incubated with glucose-free DMEM for 24 hours. The control group was incubated with high glucose DMEM under normal conditions.

\section{Analysis of cell apoptosis using flow cytometry}

The Annexin V-FITC Apoptosis Detection Kit (Abcam, ab14085) was used to detect the percentage of apoptotic and necrotic HK-2 cells by flow cytometry. After treatment, HK-2 cells were collected and washed twice with cold PBS. The cells were resuspended in $500 \mu \mathrm{L} 1 \times$ binding buffer and incubated with $5 \mu \mathrm{L}$ fluorescein isothiocyanate (FITC) annexin $\mathrm{V}$ and $5 \mu \mathrm{L}$ propidium iodide (PI) working solution $(50 \mu \mathrm{g} / \mathrm{mL})$ in the dark for 5 minutes. Cells were then assessed using a flow cytometer (FACS Calibur, BD Biosciences, USA).

\section{Western blot}

The cell samples were centrifuged, the medium was discarded, and the cell pellet washed twice with PBS. Lysate buffer was then added to the cell pellet to extract the 
protein. The BCA Protein Analysis Kit (Thermo Fisher.) was used to measure protein concentrations. The samples were boiled for 5 minutes to denature the pre-quantified lytic products and separated by sodium dodecyl sulfate (SDS)-polyacrylamide gel electrophoresis. The separated proteins were then transferred to a polyvinylidene difluoride (PVDF) membrane (Merck millipore, Temecula, USA). The membrane was blocked with $5 \%$ skim milk solution at $25^{\circ} \mathrm{C}$ for 1 hour and washed three times in Tris-buffered saline (TBS) tween, followed by incubation with the primary antibody at $25^{\circ} \mathrm{C}$ for 2 hours. The following antibodies were used: protein kinase B (Akt; rabbit monoclonal antibody; 1:1,000; CST, cat. 4691), phosphorylated Akt (pAkt; rabbit monoclonal antibody; 1:1,000; CST, cat. T4060), caspase-3 (rabbit monoclonal antibody, 1:1,000; CST, cat. T 9662), B cell lymphoma 2 (bcl-2; rabbit polyclonal antibody; 1:2,500; Abcam, ab59348), Bax (rabbit monoclonal antibody; 1:2,500; Abcam, ab32503), cytochrome c (rabbit polyclonal antibody; 1:2,500; Abcam, ab18738), caspase-9 (mouse monoclonal antibody; 1:500; Beyotime, ac062-1), hypoxia-inducible factor 1-alpha (HIF1 $\alpha$; rabbit polyclonal antibody; 1:800; GeneTex, GTX127309), and bcl-2 interacting protein 3 (BNIP3; rabbit polyclonal antibody; 1:500; Bios, Cat. bs4239R). After repeated washing, the membranes were incubated with the corresponding HRP-conjugated secondary antibody at $4{ }^{\circ} \mathrm{C}$ for 2 hours (Carestream Health, Inc. Canada).

\section{Cell slides and TUNEL analysis}

Human HK-2 cells were cultured on slides that were precoated with polylysine (Sigma, cat. \# p9155) Cells were subjected to hypoxia-reoxygenation in the presence or absence of spermine as described above. The cells were washed twice with PBS and the apoptosis was directly detected according to the manufacturer's instructions (Promega, cat. \# G3205). Green fluorescence was observed at $520 \mathrm{~nm}$ and blue DAPI fluorescence was observed at $460 \mathrm{~nm}$ using immunofluorescence microscopy (OLYMPUS).

\section{Statistical analysis}

SPSS 25.0 software (IBM) was used for data analysis. The measurement data were expressed as mean \pm standard deviation (SD). $T$-tests were used for comparison between two groups, and analysis of variance (ANOVA) was used to evaluate the comparison between multiple groups. Results were considered statistically significant when $\mathrm{P}<0.05$.

\section{Results}

\section{Exploration of the safe dose of spermine}

Different doses of spermine ( $2 \mathrm{~mL} / \mathrm{kg}$ body weight) were injected into rats and the histology of the kidneys was examined. Before the termination of the experiment, the animals were in good health and their weight remained stable. There were 5 rats in each group (5/35). HE staining of the renal tissue showed that at $200 \mu \mathrm{mol} / \mathrm{L}$ spermine, the brush edges of the renal tubules began to fall off. Slight atrophy of the glomerulus was observed in kidneys treated with $250 \mu \mathrm{mol} / \mathrm{L}$ spermine, while significant atrophy was detected at $300 \mu \mathrm{mol} / \mathrm{L}$ (Figure 1). In rats treated with $250 \mu \mathrm{mol} / \mathrm{L}$ spermine, the levels of KIM-1 and NGAL in the venous blood was significantly higher compared to the levels in control animals and in rats treated with 50 $200 \mu \mathrm{mol} / \mathrm{L}$ spermine. These results demonstrated that at a dose of $2 \mathrm{~mL} / \mathrm{kg}$ body weight, spermine at a concentration of $200 \mu \mathrm{mol} / \mathrm{L}$ or less was non-toxic to the rat kidney (Figure 2).

\section{Periodic acid Schiff (PAS) staining was used to analyze the brush edge of renal tubules}

PAS staining showed that the brush edge of renal tubules in the negative control group (sham operation) was intact without obvious pathological changes. The positive control group (ischemia-reperfusion model without drug treatment) had more visual field to see the brush edge of renal tubules falling off and structural disorder. In the spermine intervention group, the brush edge of the renal tubules was only partially shed, and the degree of shedding was less than that observed in the positive control group. When the concentration of spermine reached $150 \mu \mathrm{mol} / \mathrm{L}$, only a small amount of brush edge shedding and structural disorder could be observed (Figure 3).

\section{The TUNEL analysis was used to detect apoptosis in rat kidneys}

TUNEL analysis showed that only a few cells in the negative control group (sham operation) were apoptotic, while a large number of cells in the positive control group (ischemia-reperfusion model without drug treatment) were apoptotic. The degree of apoptosis of renal tubular epithelial cells in the drug intervention group was less than that in positive control group. Increasing the drug concentration further decreased the apoptosis of renal tubular epithelial cells (Figure 4). 


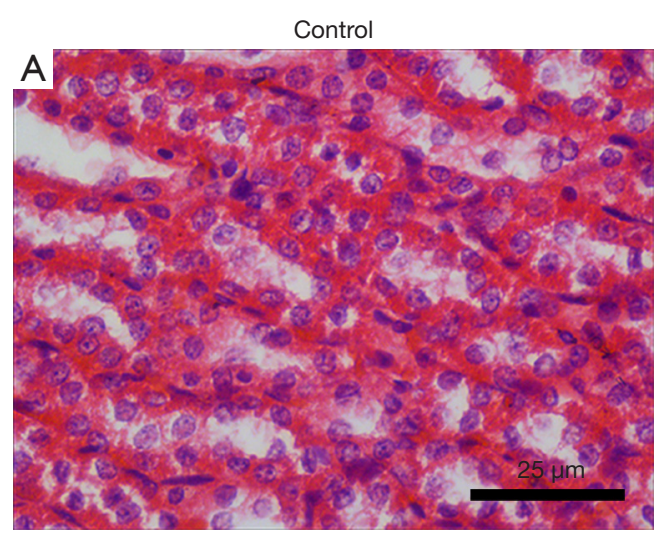

$250 \mu \mathrm{M}$

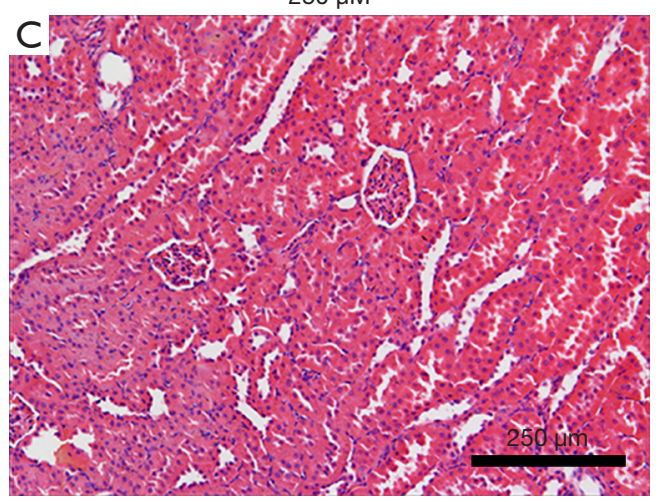

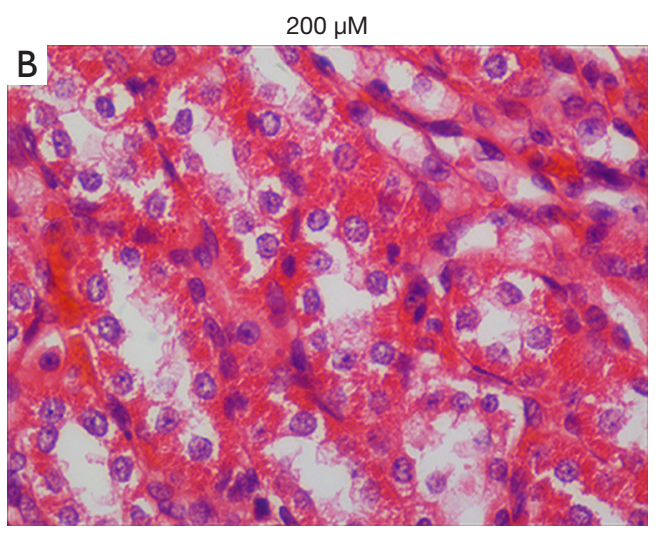

$300 \mu \mathrm{M}$

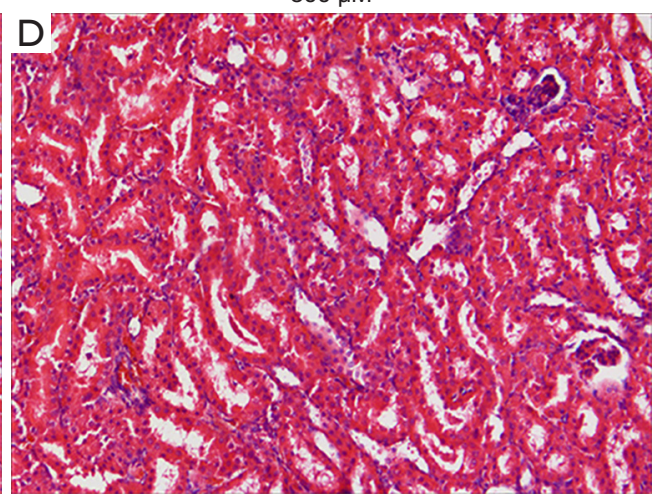

Figure 1 Hematoxylin and eosin (HE) staining of rat kidneys to evaluate the effect of different concentrations of exogenous spermine on renal tissue structure. (A) In the control group, the same volume $(2 \mathrm{~mL} / \mathrm{kg}$ body weight $)$ of saline was injected into the tail veins of rats. HE staining showed that the renal tissue structure was normal; (B) at $200 \mu \mathrm{M}$ spermine, the brush-like edges of the renal tubules began to fall off. (C) increasing the concentrations to $250 \mu \mathrm{M}$ spermine resulted in mild atrophy of the glomeruli; (D) as the concentration of spermine further increased to $300 \mu \mathrm{M}$, obvious glomerular atrophy could be observed.

A

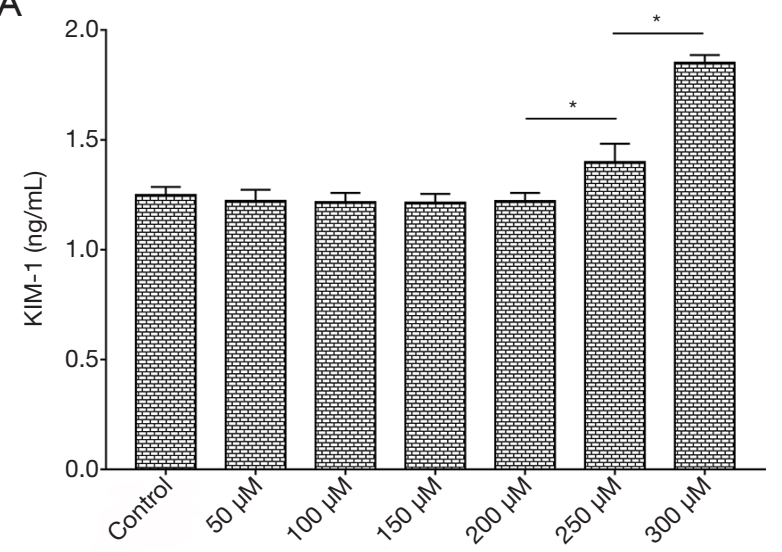

B

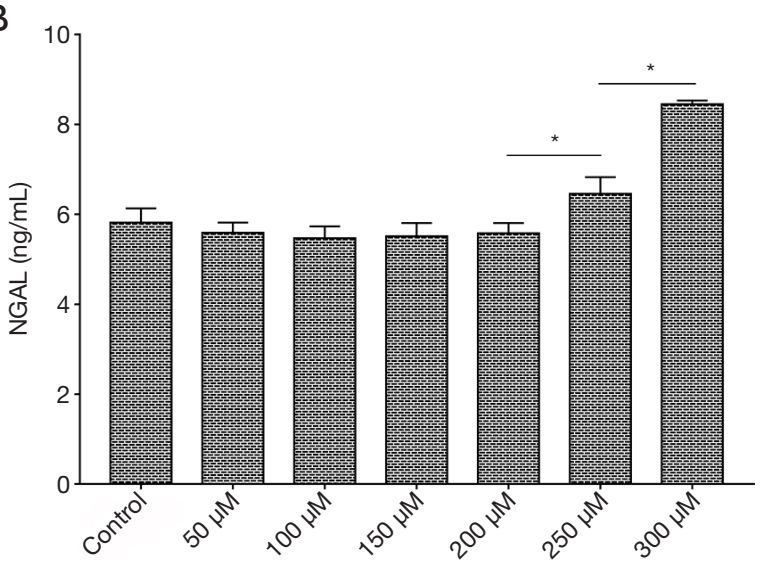

Figure 2 ELISA analysis of the levels of KIM-1 and NGAL in rat venous blood to evaluate the toxic effect of exogenous spermine on rat kidney and to explore the safe dose range. (A) Changes of KIM-1 in rat blood after different concentrations of spermine intervention. (B) Changes of NGAL in rat blood after different concentrations of spermine intervention. ${ }^{*} \mathrm{P}<0.05$. KIM-1, kidney injury molecule 1 ; NGAL, neutrophil gelatinase-associated lipocalin. When the concentration of spermine reached $250 \mu \mathrm{mol} / \mathrm{L}$, the levels of KIM-1 and NGAL in rat blood began to increase significantly. 

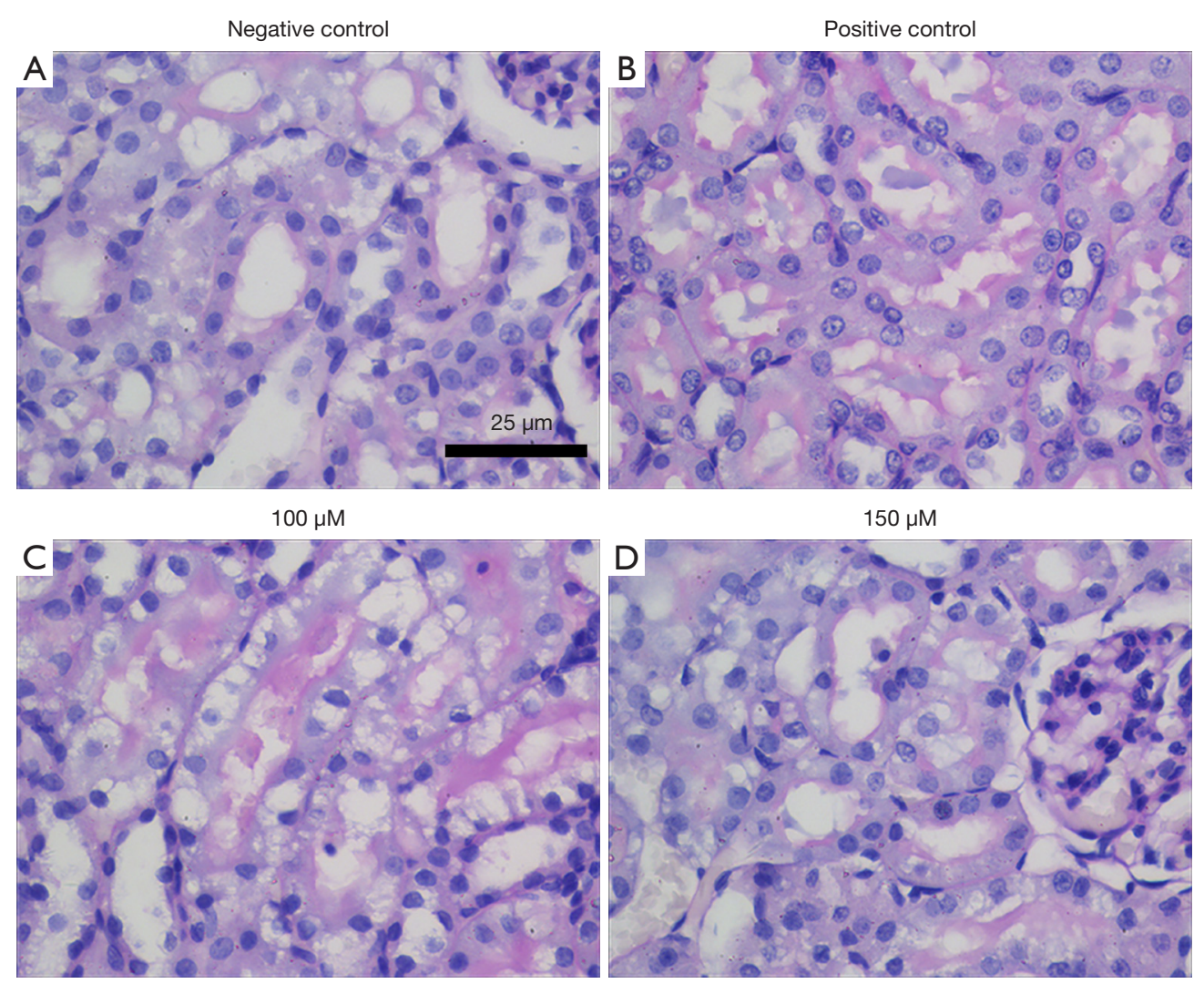

Figure 3 PAS staining of kidney sections. (A) In the negative control group (sham operation), the brush edge of the renal tubules is intact; (B) in the positive control (ischemia-reperfusion model without drug treatment) the brush edge of the renal tubules have fallen off and the structure is disordered; (C,D) the ischemia-reperfusion rats were treated with spermine. At the lower concentration of $100 \mu M(C)$, the brush edge of the renal tubules has fallen off, but to a lesser extent compared to the positive control group. Increasing the drug concentration to $150 \mu \mathrm{M}$ (D) further reduced the degree of brush edge shedding and structural disorder.

\section{Detection of kidney injury molecule 1 (KIM-1) and neutrophil gelatinase-associated lipocalin (NGAL) in rat blood}

There were 5 rats in each group (5/20). KIM-1 and NGAL are commonly used markers to evaluate renal injury. ELISA analysis showed that blood concentrations of KIM1 and NGAL were significantly higher in rats undergoing ischemia reperfusion injury compared to the sham operation control animals $(1.82 \pm 0.05$ vs. $1.24 \pm 0.04 \mathrm{ng} / \mathrm{mL}$ and $8.70 \pm 0.44$ vs. $5.45 \pm 0.09 \mathrm{ng} / \mathrm{mL}$, respectively; $\mathrm{P}<0.05$ ). However, in ischemia reperfusion animals, treatment with spermine significantly reduced the levels of both KIM-1 and NGAL in a dose-dependent manner compared to untreated animals $(\mathrm{P}<0.05$; Figure 5).

\section{TUNEL cell apoptosis detection}

By making HK-2 cell climbing slices, TUNEL cell apoptosis detection showed that the number of apoptotic HK-2 cells after hypoxia-reoxygenation culture was reduced in samples treated with spermine, and the effect was more obvious with the increase of spermine concentration (Figure 6).

\section{Flow cytometry analysis}

Flow cytometry analysis revealed that the rate of apoptosis (early apoptosis + late apoptosis) in the control group, the $\mathrm{H} / \mathrm{R}$ group, the $\mathrm{H} / \mathrm{R}+10 \mu \mathrm{M}$ spermine group, and the $\mathrm{H} / \mathrm{R}+50 \mu \mathrm{M}$ spermine group were $4.97 \% \pm 0.52 \%$, $32.86 \% \pm 1.82 \%, 15.43 \% \pm 1.48 \%$, and $9.41 \% \pm 1.33 \%$, respectively $(\mathrm{P}<0.05$; Figure 7$)$.

\section{Western blot analysis}

Western blot analysis showed that the expression of HIF-1 $\alpha$, 

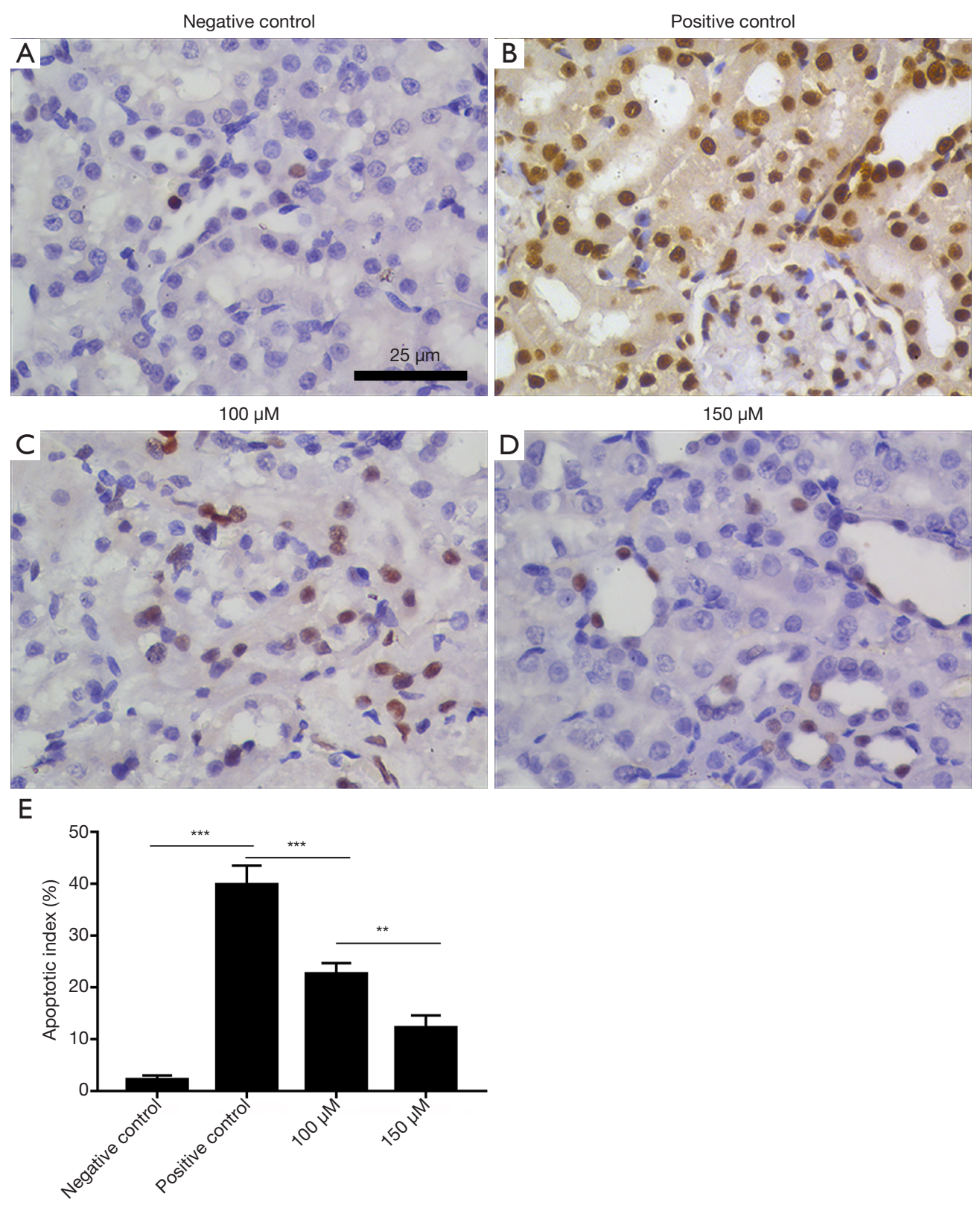

Figure 4 The detection of apoptosis via the TUNEL assay. (A) The negative control shows cells from the sham operation group with only a few apoptotic cells in the renal tubules. (B) The positive control shows cells from rats that underwent ischemia-reperfusion injury. The representative image shows a large number of apoptotic renal tubular cells. (C,D) Rats undergoing ischemia-reperfusion injury were treated with spermine (100 and $150 \mu \mathrm{M}$, respectively). There are significantly fewer apoptotic renal tubular cells compared to the positive control, and the number of apoptotic cells decreases further with increasing concentrations of spermine. (E) A histogram showing the apoptotic index. ${ }^{* *} \mathrm{P}<0.01,{ }^{* * *} \mathrm{P}<0.001$.

p-Akt, pro-caspase 9, Bcl-2, and BNIP3 were up-regulated after spermine treatment. The expression of cytochrome C, cleaved caspase-3, and Bax were down-regulated. The gray value of $\mathrm{p}$-Akt was compared to that of Akt, and other protein bands were compared to glyceraldehyde 3-phosphate dehydrogenase (GAPDH) (Figure 8). 
A

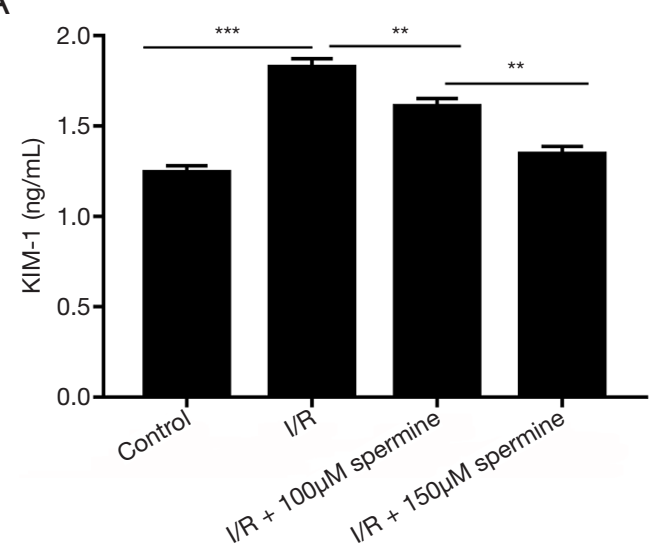

B

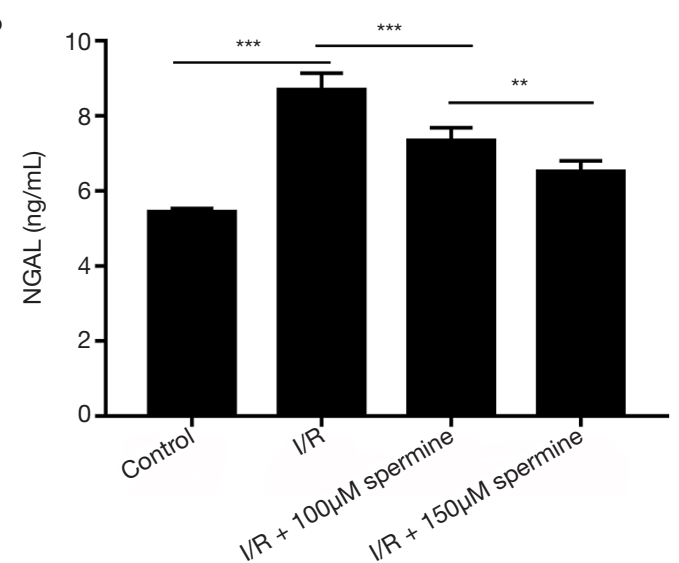

Figure 5 Detection of (A) KIM-1 and (B) NGAL in rat blood by ELISA. (A) The concentration of KIM-1 in the blood of rats in different treatment groups. (B) The concentration of NGAL in the blood of rats in different treatment groups. ${ }^{* *} \mathrm{P}<0.01,{ }^{* * *} \mathrm{P}<0.001$. KIM-1, kidney injury molecule 1; NGAL, neutrophil gelatinase-associated lipocalin; I/R, ischemia reperfusion.

\section{Discussion}

The mechanism of renal ischemia-reperfusion injury mainly includes energy metabolism disorder, calcium overload, mitochondrial injury, oxidative stress, inflammation, apoptosis and autophagy (28). Among them, autophagy of renal tubular epithelial cells is a new hotspot. During the occurrence and development of acute kidney injury, the key sites of autophagy related signaling pathway may provide a new strategy for the treatment of acute kidney injury (29). However, the role of autophagy in renal ischemiareperfusion injury remains controversial. Whether the upregulated autophagy plays a protective role in the kidney or aggravates renal injury remains controversial. On the one hand, autophagy can degrade abnormal proteins and organelles in abnormal cells, prevent the accumulation of harmful substances, and play a protective role in the survival of cells (30); on the other hand, excessive levels of autophagy can damage organelles and make them transform into autophagy cell death (31). Therefore, the mechanism of autophagy on renal ischemia-reperfusion injury needs further study. Currently, there is no ideal drug for renal ischemia-reperfusion injury. TLR2 antibody is a new drug that has entered the second phase of clinical trials, and its effect needs to be further observed.

To date, there have been few studies examining the protective effects of spermine on ischemia-reperfusion injury. Studies by $\mathrm{Xu}$ and colleagues demonstrated that myocardial ischemia and myocardial ischemia-reperfusion can cause changes in polyamine metabolism. They demonstrated that ischemia-reperfusion led to the depletion of the myocardial polyamine pool, and the loss of spermine may be related to myocardial ischemia-reperfusion injury. Exogenous spermine could restore the intracellular polyamine pool and protect myocardial ischemia-reperfusion injury (24) . However, the protective effects of spermine on renal ischemia-reperfusion injury has not been previously reported. This current study is the first to evaluate the toxic effects of spermine on the rat kidney and identify a safe dose range. While the toxic effects of drugs often involve a wide range of organs, the main research focus of this investigation was the kidneys. This study demonstrated that when rats were administered $200 \mu \mathrm{mol} / \mathrm{L}$ spermine at a dose of $2 \mathrm{~mL} / \mathrm{kg}$ body weight, pathological changes could be observed in the kidneys, and the levels of the kidney injury markers KIM-1 and NGAL began to increase significantly.

Therefore, a spermine concentration below $200 \mu \mathrm{mol} / \mathrm{L}$ was subsequently used for animal experiments. Histological PAS staining, TUNEL cell apoptosis assay, and KIM1 and NGAL levels in the blood all demonstrated that exogenous spermine had a protective effect on renal ischemia-reperfusion injury. As KIM-1 cannot be detected in normal renal tissue but is only expressed in injured proximal tubules, it is a highly sensitive, specific, and accurate early biomarker of renal tubular injury (32). NGAL is also a sensitive biomarker for the early diagnosis of acute renal injury and acute renal failure. Generally, NGAL levels are significantly increased within one hour of acute renal failure, and it is related to the severity of renal injury (33). Therefore, the combination of KIM-1 and NGAL detection 


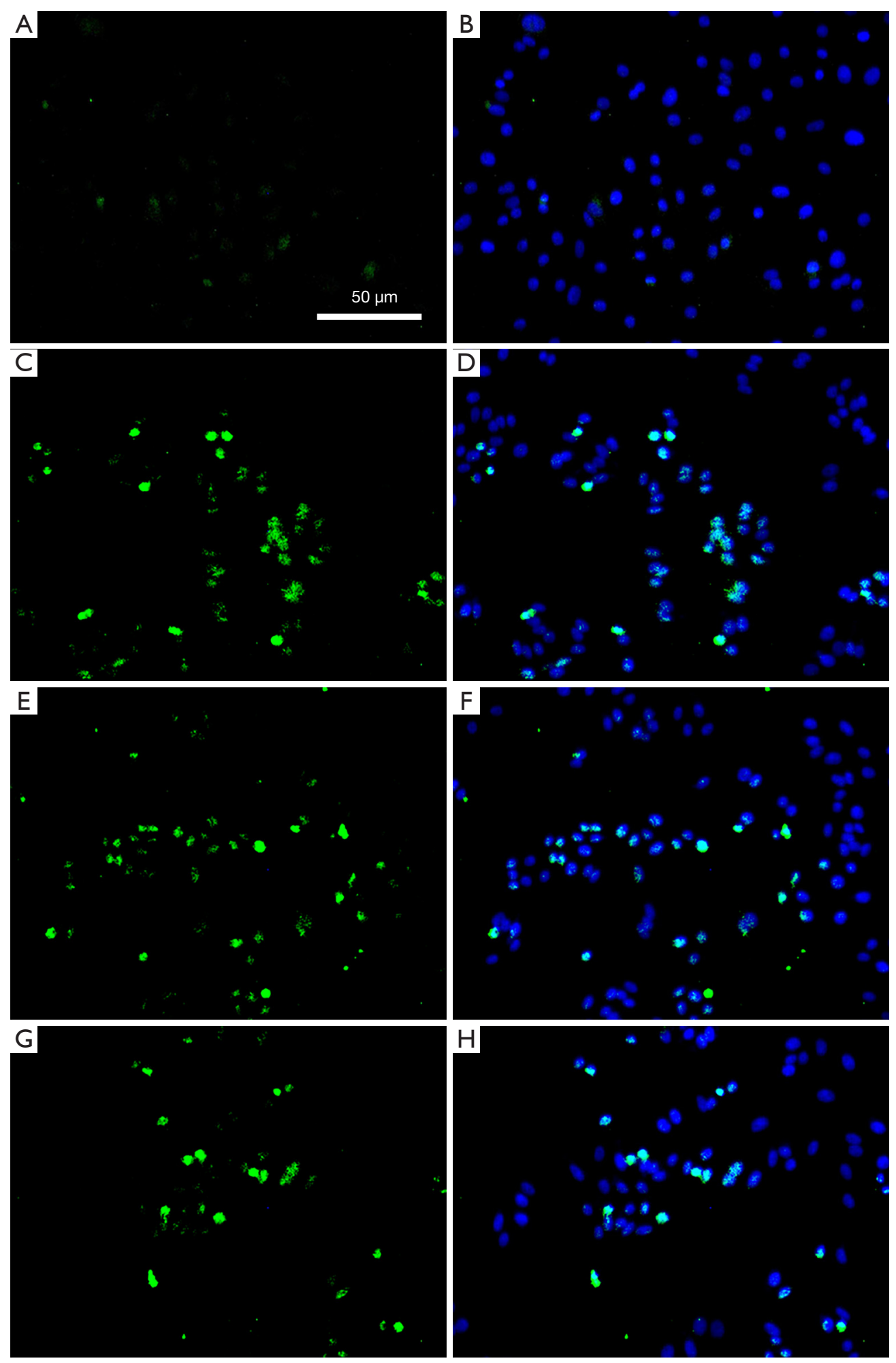

Figure 6 Cell apoptosis via TUNEL detection. (A,B) Control group in which HK-2 cells were cultured without any treatment; (C,D) positive control group in which cells were exposed to hypoxia-reoxygenation (H/R) to simulate ischemia-reperfusion injury; (E,F) the H/R + $10 \mu \mathrm{M}$ spermine group in which cells exposed to H/R were treated with $10 \mu M$ spermine; $(\mathrm{G}, \mathrm{H})$ the $\mathrm{H} / \mathrm{R}+50 \mu \mathrm{M}$ spermine group in which cells exposed to $\mathrm{H} / \mathrm{R}$ were treated with $50 \mu \mathrm{M}$ spermine. 
A

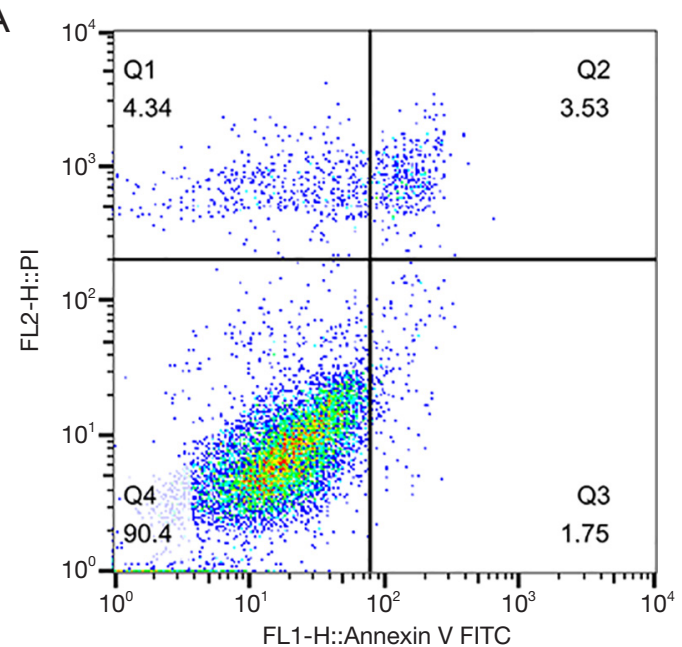

C

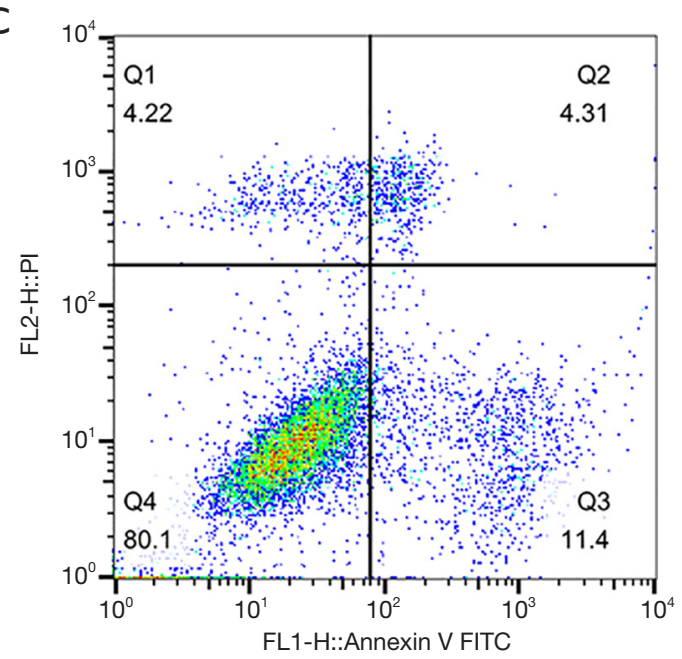

B

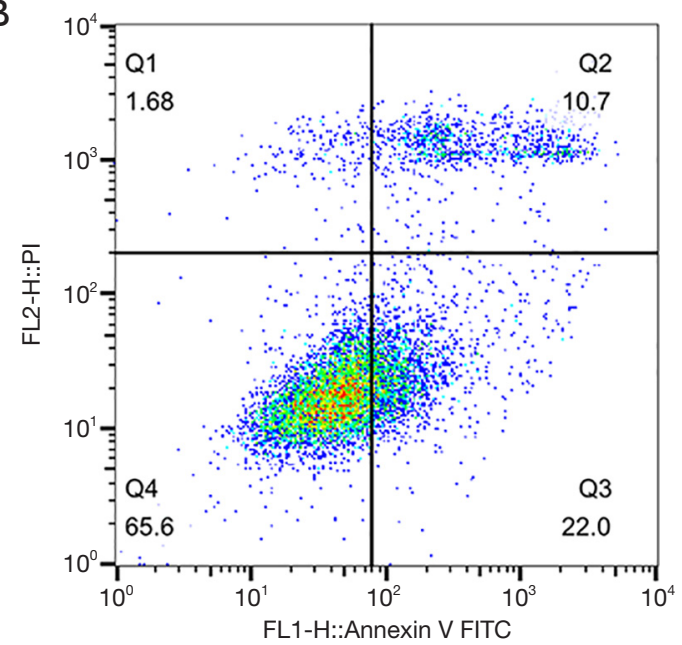

D

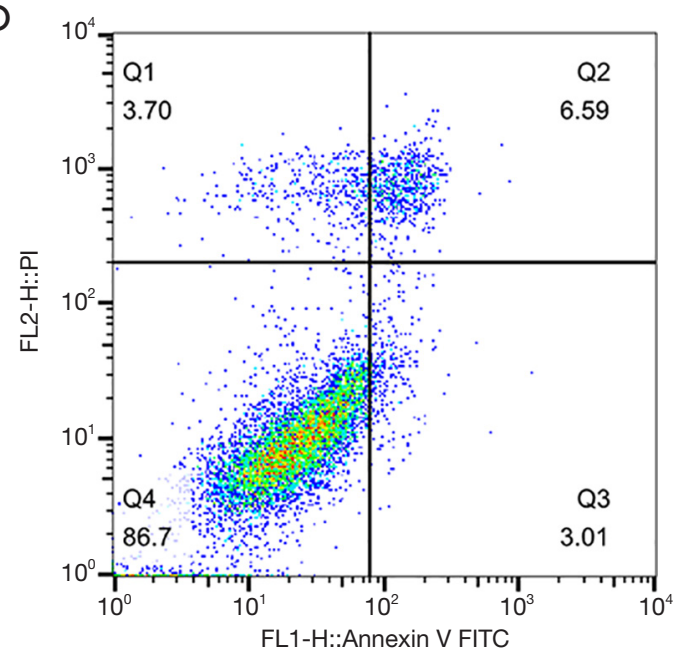

\section{$\mathrm{E}$}

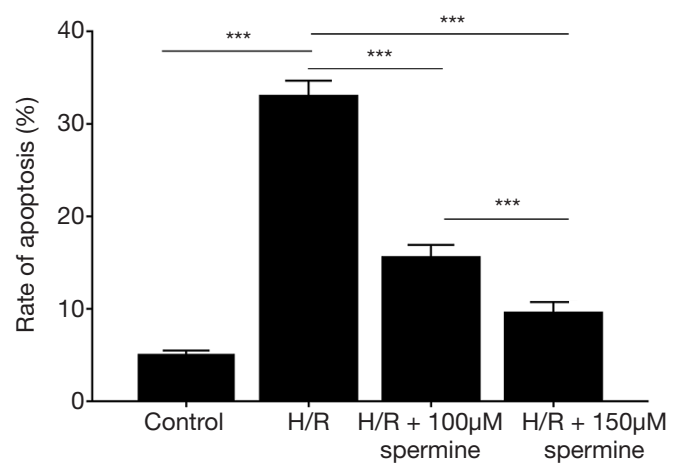

Figure 7 Flow cytometry analysis. (A) Control group in which HK-2 cells did not receive any intervention; (B) the positive control group in which cells underwent hypoxia-reoxygenation (H/R) to simulate ischemia/reperfusion injury; (C) the H/R + $10 \mu M$ spermine intervention group in which cells exposed to $H / R$ were treated with $10 \mu \mathrm{M}$ spermine; (D) the $\mathrm{H} / \mathrm{R}+50 \mu \mathrm{M}$ spermine intervention group in which cells exposed to H/R were treated with $50 \mu \mathrm{M}$ spermine; (E) a graph showing the average rate of apoptosis in each group of cells. ${ }^{* * *} \mathrm{P}<0.001$. 


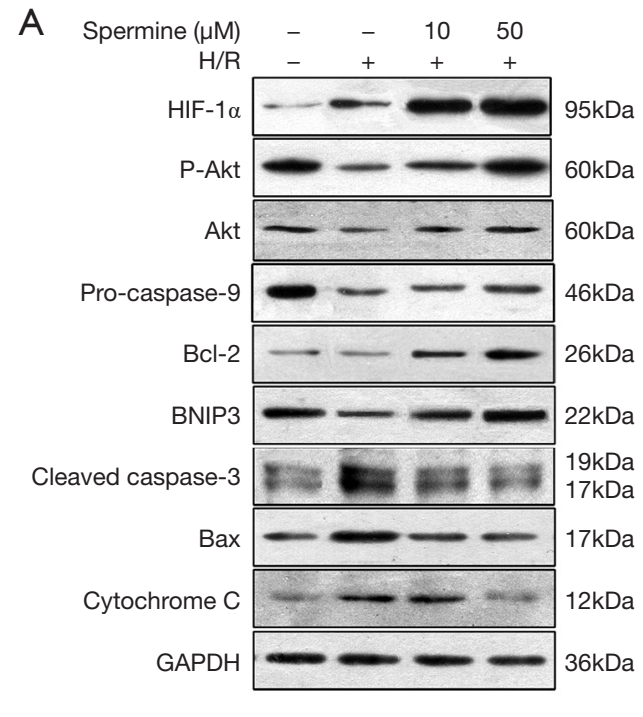

C

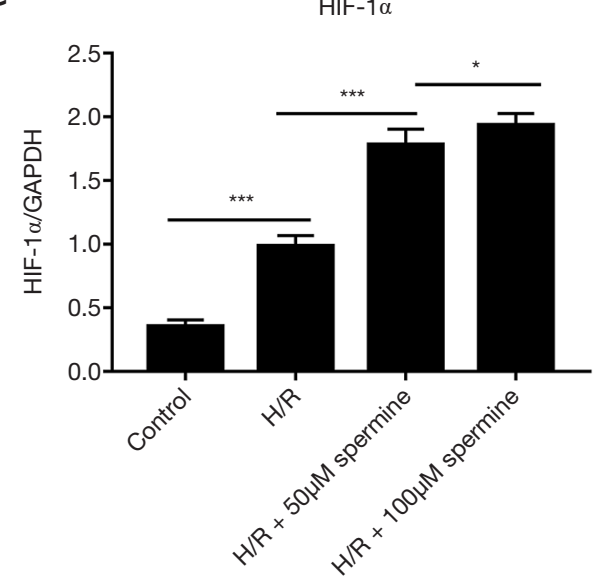

$E$

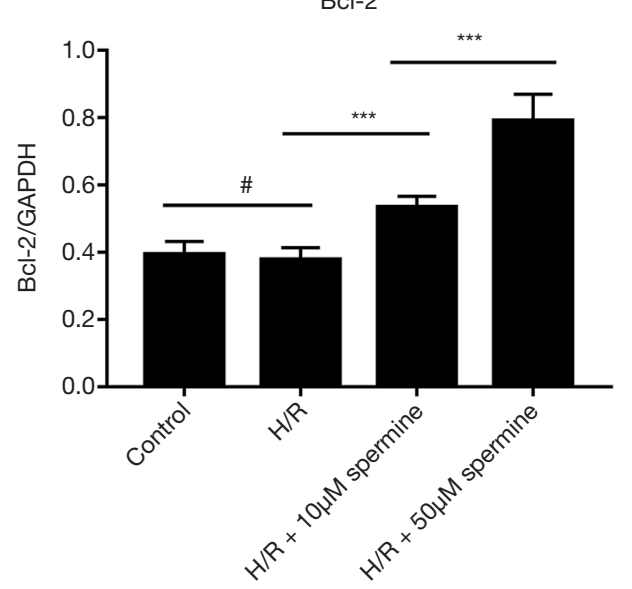

B

p-AKT

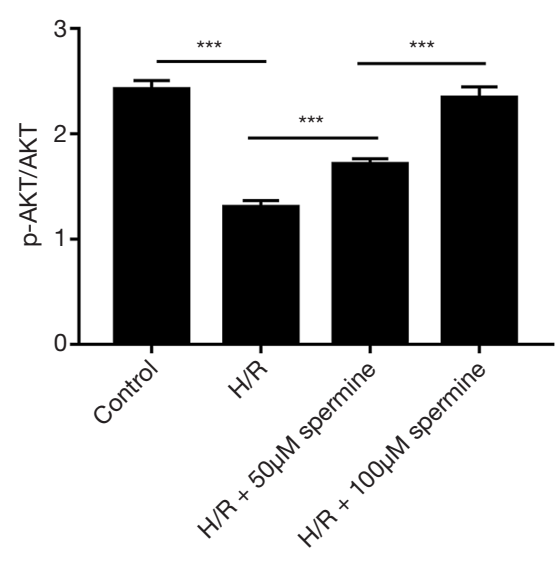

D

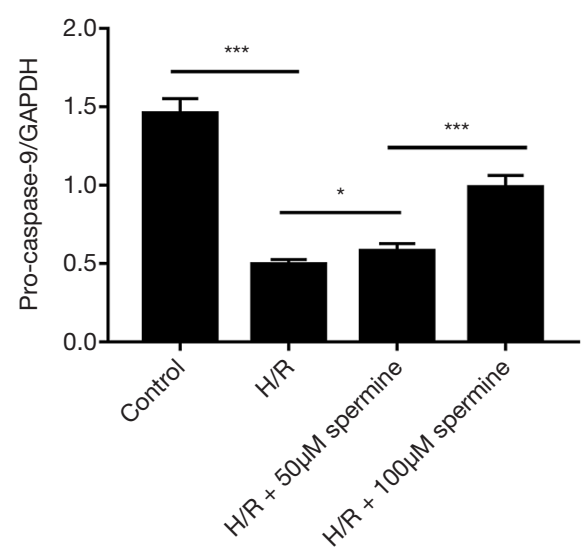

F

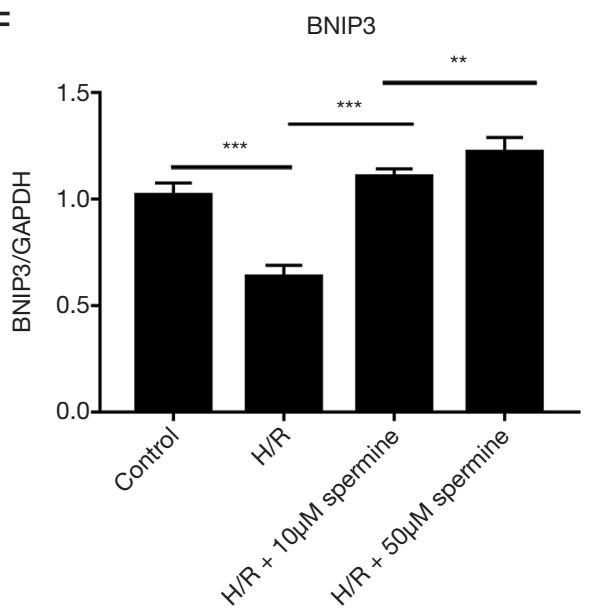


G
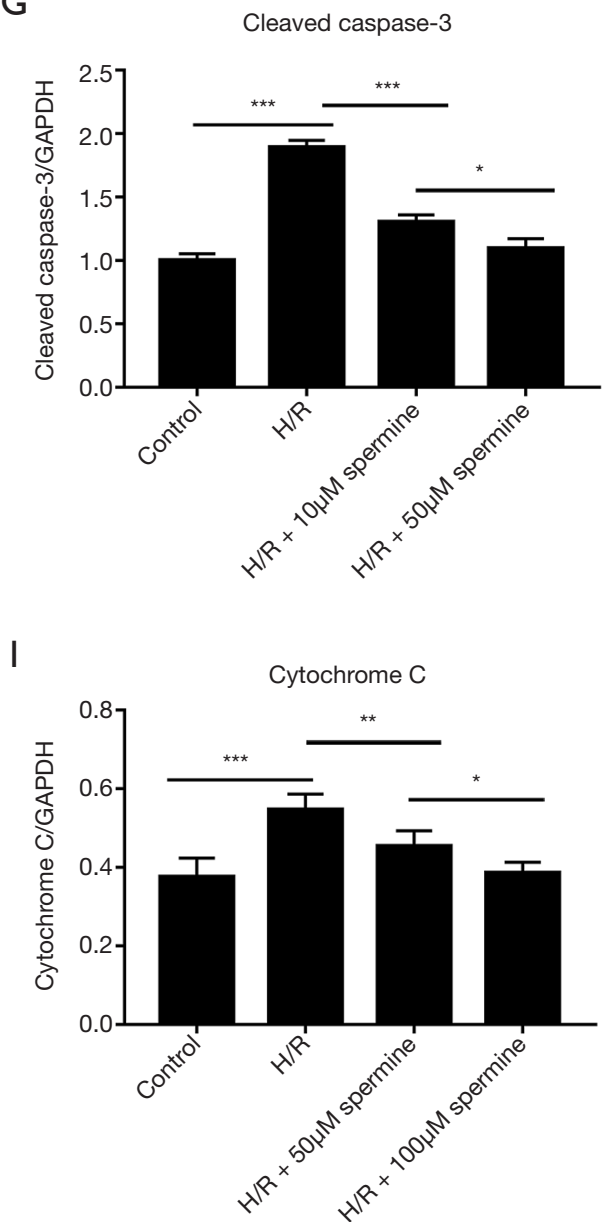

$\mathrm{H}$

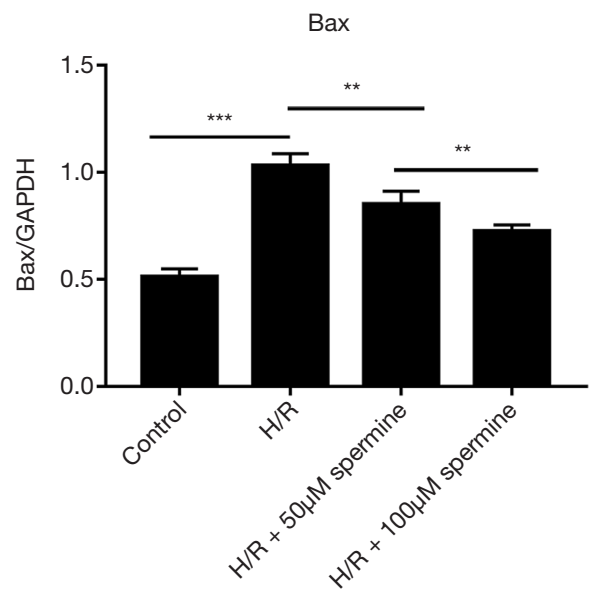

Figure 8 Analysis of Western blot bands and the average gray value in each group.(8) Representative bands of Western blot analysis; (B) the gray value of p-Akt was analyzed with Akt as internal reference; (C) gray value analysis of HIF-1 $\alpha$ in different treatment groups; (D) gray value analysis of pro-caspase-9 in different treatment groups; (E) gray value analysis of Bcl-2 in different treatment groups; (F) gray value analysis of BNIP3 in different treatment groups; (G) gray value analysis of cleaved caspase-3 in different treatment groups; (H) gray value analysis of Bax in different treatment group; (I) gray value analysis of cytochrome in different treatment group. ${ }^{*} \mathrm{P}<0.05,{ }^{* *} \mathrm{P}<0.01$, ${ }^{* * *} \mathrm{P}<0.001,{ }^{\#} \mathrm{P}>0.05 . \mathrm{H} / \mathrm{R}$, hypoxia/reoxygenation; HIF-1a, hypoxia inducible factor 1 alpha; Akt, protein kinase B; p-Akt, phosphorylated Akt; Bcl-2, B cell lymphoma 2; BNIP3, Bcl-2 interacting protein 3; GAPDH, glyceraldehyde 3-phosphate dehydrogenase.

can efficiently evaluate the location and degree of renal injury. Due to the high similarity of rat and human genomes, the animal research results may also be applicable to human. However, the specific mechanisms of the protective effects of exogenous spermine on renal ischemia-reperfusion injury in rats remain unclear. Since apoptosis is a common pathological mechanism of renal ischemia-reperfusion injury, the effects of spermine on cell apoptosis was examined in vitro.

To investigate the protective mechanisms of spermine on renal ischemia-reperfusion injury, HK-2 human renal tubular epithelial cells were cultured in vitro and a hypoxia- reoxygenation model was constructed to simulate ischemiareperfusion injury. TUNEL and flow cytometry analyses demonstrated that spermine reduced the apoptosis of HK-2 human renal tubular epithelial cells. Apoptosis is triggered by a variety of stimuli, including cell surface receptors such as FAS, mitochondrial responses to stress, and cytokines released by cytotoxic $\mathrm{T}$ cells. Mitochondrial stress pathways begin with the release of cytochrome $\mathrm{C}$ from the mitochondria, which then interacts with apoptotic protease activating factor 1 (Apaf-1), resulting in the cleavage and activation of caspase- 9 . The caspase family is closely related 
to apoptosis and plays a key role in the initiation and execution of apoptosis. Caspase-9 is located upstream of the cascade, and belongs to the subclass of proteins involved in apoptosis initiation and participates in the initiation of downstream caspase proteases. Caspase- 3 is located downstream of the cascade reaction, and is a subclass related to direct cell apoptosis. Western blot analysis revealed that the expression of pro-caspase- 9 in the spermine intervention group was higher than that in the H/R group, and the expression of cytochrome $\mathrm{C}$ and cleaved caspase- 3 in the spermine intervention group were lower than that observed in the H/R group. These results indicated that the mitochondrial activated apoptosis pathway is inhibited in HK-2 cells after spermine intervention.

The study also showed that the expression of Bcl2 increased and while the expression of Bax decreased in HK-2 cells after spermine treatment. Bax and Bcl-2 belong to the bcl-2 gene family. Studies have shown that Bcl-2 can prevent the release of cytochrome $\mathrm{C}$ from the mitochondria to the cytoplasm, thereby inhibiting apoptosis (34). Bax not only antagonizes the inhibitory effect of Bcl-2, but also promotes apoptosis and plays a key role in mitochondrial stress-induced apoptosis. Bax is mainly located in the cytoplasm in the form of a monomer (35). The monomer Bax cannot stimulate the release of cytochrome $\mathrm{C}$, but Bax can form oligomers, transfer from the cytoplasm to the mitochondrial membrane, form a polymer with Bcl2 , enhance the permeability of the mitochondria, and finally facilitate the release of cytochrome $\mathrm{C}(36,37)$. This results in the activation of caspase-9, activation of the caspase protease family, and subsequently, mitochondriamediated cell apoptosis (38). BNIP3 is a pro-apoptotic protein that can antagonize the anti-apoptotic effects of Bcl-2 by forming isomers with Bcl-2 (39). Therefore, the up regulation of Bcl-2 and the down regulation of Bax and BNIP3 results in decreased apoptosis.

Western blot analysis showed that the expression of hypoxia inducible factor- $1 \alpha$ (HIF-1 $\alpha$ ) in HK-2 cells was significantly down-regulated after spermine treatment. HIF- $1 \alpha$ is an important transcription factor in cells under hypoxia. Under normal physiological conditions, HIF-1 $\alpha$ can be degraded by the ubiquitin protease pathway. When cells are stimulated by hypoxia, the degradation of HIF$1 \alpha$ is inhibited, resulting in an accumulation of HIF- $1 \alpha$ in the cells. By regulating the expression of its target genes, the energy metabolism of cells is maintained. Many studies have shown that the translation rate of HIF- $1 \alpha$ is regulated by the Akt/mechanistic target of rapamycin (mTOR)- dependent transduction pathway and is unrelated to hypoxic tension. HIF- $1 \alpha$ is crucial for the recovery of acute tubular necrosis and may play a key role in the outcome of graft transplantation $(10,40)$. The results of the current study demonstrated that Akt was significantly activated in the spermine intervention group in a dose-dependent manner, suggesting that the expression of HIF- $1 \alpha$ was related to the activation of Akt/mTOR pathway.

It is generally believed that HIF- $1 \alpha$-mediated responses vary depending on whether the hypoxic conditions are acute or chronic, or mild or severe. The main determinant of whether HIF- $1 \alpha$ mediates injury or exerts a protective effect is the intensity and duration of the HIF- $1 \alpha$ activation. The activation of HIF- $1 \alpha$ can protect the myocardium in acute myocardial ischemia, but it can damage the myocardium in chronic hypoxia. It is possible that HIF- $1 \alpha$ regulates the metabolic modes of cells, which can adapt to shortterm hypoxia, but cannot adapt to long-term hypoxia. The final outcome of HIF-1 $\alpha$ depends on the balance between various factors and reactions $(41,42)$.

HIF-1 $\alpha$ can induce the expression of BNIP3. Western blot analysis showed that increased expression of HIF-1a is correlated with increased expression of BNIP3 in HK2 cells. Previous studies have suggested that BNIP3 is a proapoptotic protein which is closely related to cell death (43). However, some recent studies have found that BNIP3 may participate in autophagy and increase cell survival (44-46). Bellot et al. $(44,47)$ also demonstrated that hypoxia or severe hypoxia increased the expression of BNIP3 in an HIF- $1 \alpha$-dependent manner, induced the occurrence of mitochondrial autophagy, and prevented cell death.

The main findings of this investigation suggested that exogenous spermine inhibits apoptosis associated with renal ischemia-reperfusion injury by inhibiting the classical mitochondrial stress pathway. Alternatively, spermine may alleviate the ischemia-reperfusion injury of HK-2 cells by activating the Akt/mTOR/HIF-1 $\alpha /$ BNIP3 pathway.

\section{Acknowledgments}

Funding: This work was supported by the joint fund of Guizhou provincial Science \& Technology Department and Guizhou provincial People's Hospital [grant number: LH(2016)7164].

\section{Footnote}

Reporting Checklist: The authors have completed the 
ARRIVE reporting checklist. Available at http://dx.doi. org/10.21037/tau-21-280

Data Sharing Statement: Available at http://dx.doi. org/10.21037/tau-21-280

Conflicts of Interest: All authors have completed the ICMJE uniform disclosure form (available at http://dx.doi. org/10.21037/tau-21-280). The authors have no conflicts of interest to declare.

Ethical Statement: The authors are accountable for all aspects of the work in ensuring that questions related to the accuracy or integrity of any part of the work are appropriately investigated and resolved. Experiments were performed under a project license (NO.: 2020-065) granted by ethics board of Guizhou Provincial People's Hospital, in compliance with China national or institutional guidelines for the care and use of animals.

Open Access Statement: This is an Open Access article distributed in accordance with the Creative Commons Attribution-NonCommercial-NoDerivs 4.0 International License (CC BY-NC-ND 4.0), which permits the noncommercial replication and distribution of the article with the strict proviso that no changes or edits are made and the original work is properly cited (including links to both the formal publication through the relevant DOI and the license). See: https://creativecommons.org/licenses/by-nc-nd/4.0/.

\section{References}

1. Eltzschig HK, Eckle T. Ischemia and reperfusion--from mechanism to translation. Nat Med 2011;17:1391-401.

2. Korkmaz A, Kolankaya D. Inhibiting inducible nitric oxide synthase with rutin reduces renal ischemia/reperfusion injury. Can J Surg 2013;56:6-14.

3. Shen H, Kreisel D, Goldstein DR. Processes of Sterile Inflammation. J Immunol 2013;191:2857-63.

4. Wang $\mathrm{Y}, \mathrm{He} \mathrm{J}$, Pei XH, et al. Systematic review and meta-analysis of mesenchymal stem/stromal cells therapy for impaired renal function in small animal models. Nephrology 2013;18:201-8.

5. Kalyanaraman B. Teaching the basics of redox biology to medical and graduate students: Oxidants, antioxidants and disease mechanisms. Redox Biology 2013;1:244-57.

6. Lafrance JP, Miller DR. Acute Kidney Injury Associates with Increased Long-Term Mortality. J Am Soc Nephrol
2010;21:345-52.

7. Smith SF, Hosgood SA, Nicholson ML. Ischemia-reperfusion injury in renal transplantation: 3 key signaling pathways in tubular epithelial cells. Kidney Int 2019;95:50-6.

8. Wu H, Chadban SJ. Roles of Toll-like receptors in transplantation. Curr Opin Organ Transplant 2014;19:1-7.

9. Koch A, Pfeilschifter J, Huwiler A. Sphingosine 1-Phosphate in Renal Diseases. Cell Physiol Biochem 2013;31:745-60.

10. Akhtar MZ, Sutherland AI, Huang H, et al. The Role of Hypoxia-Inducible Factors in Organ Donation and Transplantation: The Current Perspective and Future Opportunities. Am J Transplant 2014;14:1481-7.

11. Farrar CA, Keogh B, McCormack W, et al. Inhibition of TLR2 promotes graft function in a murine model of renal transplant ischemia-reperfusion injury. FASEB J 2012;26:799-807.

12. Reilly M, Miller RM, Thomson MH, et al. Randomized, Double-Blind, Placebo-Controlled, Dose-Escalating Phase I, Healthy Subjects Study of Intravenous OPN-305, a Humanized Anti-TLR2 Antibody. Clin Pharmacol Ther 2013;94:593-600.

13. Kadono K, Uchida Y, Hirao H, et al. Thrombomodulin Attenuates Inflammatory Damage Due to Liver Ischemia and Reperfusion Injury in Mice in Toll-Like Receptor 4-Dependent Manner. Am J Transplant 2017;17:69-80.

14. Pegg AE. The function of spermine. IUBMB Life 2014;66:8-18.

15. Igarashi K, Kashiwagi K. Polyamines: mysterious modulators of cellular functions. Biochem Biophys Res Commun 2000;271:559-64.

16. Igarashi K, Kashiwagi K. Modulation of cellular function by polyamines. Int $\mathrm{J}$ Biochem Cell Biol 2010;42:39-51.

17. Larque E, Sabater-Molina M, Zamora S. Biological significance of dietary polyamines. Nutrition 2007;23:87-95.

18. Moinard C, Cynober L, de Bandt JP. Polyamines: metabolism and implications in human diseases. Clin Nutr 2005;24:184-97.

19. Pegg AE. Toxicity of Polyamines and Their Metabolic Products. Chem Res Toxicol 2013;26:1782-800.

20. Ramani D, De Bandt JP, Cynober L. Aliphatic polyamines in physiology and diseases. Clin Nutr 2014;33:14-22.

21. Eisenberg T, Abdellatif $M$, Schroeder S, et al. Cardioprotection and lifespan extension by the natural polyamine spermidine. Nat Med 2016;22:1428-38.

22. Bonneau MJ, Poulin R. Spermine oxidation leads to necrosis with plasma membrane phosphatidylserine redistribution in mouse leukemia cells. Exp Cell Res 2000;259:23-34. 
23. Seiler N, Raul F. Polyamines and apoptosis. J Cell Mol Med 2005;9:623-42.

24. Zhao YJ, Xu CQ, Zhang WH, et al. Role of polyamines in myocardial ischemia/reperfusion injury and their interactions with nitric oxide. Eur J Pharmacol 2007;562:236-46.

25. Wang WY, Meng LJ, Xu YJ, et al. Effects of 4\% paraformaldehyde and modified Davidson's fluid on the morphology and immunohistochemistry of Xiang pig testes. J Toxicol Pathol 2020;33:97-104.

26. Grosset AA, Loayza-Vega K, Adam-Granger E, et al. Hematoxylin and Eosin Counterstaining Protocol for Immunohistochemistry Interpretation and Diagnosis. Appl Immunohistochem Mol Morphol 2019;27:558-63.

27. Liu S, Ai Q, Feng K, et al. The cardioprotective effect of dihydromyricetin prevents ischemia-reperfusion-induced apoptosis in vivo and in vitro via the PI3K/Akt and HIF1alpha signaling pathways. Apoptosis 2016;21:1366-85.

28. Tan XH, Zheng XM, Yu LX, et al. Fibroblast growth factor 2 protects against renal ischaemia/reperfusion injury by attenuating mitochondrial damage and proinflammatory signalling. J Cell Mol Med 2017;21:2909-25.

29. Jia H, Yan Y, Liang Z, et al. Autophagy: A new treatment strategy for MSC-based therapy in acute kidney injury. Mol Med Rep 2018;17:3439-47.

30. Bao DS, Wu YK, Fu SJ, et al. Hyperbaric Oxygenation Protects Against Ischemia-Reperfusion Injury in Transplanted Rat Kidneys by Triggering Autophagy and Inhibiting Inflammatory Response. Ann Transplant 2017;22:75-82.

31. Kasprowska-Liskiewicz D. The cell on the edge of life and death: Crosstalk between autophagy and apoptosis. Postepy Hig Med Dosw (Online) 2017;71:825-41.

32. Han WK, Bailly V, Abichandani R, et al. Kidney Injury Molecule-1 (KIM-1): a novel biomarker for human renal proximal tubule injury. Kidney Int 2002;62:237-44.

33. Bolignano D, Donato V, Coppolino G, et al. Neutrophil gelatinase-associated lipocalin (NGAL) as a marker of kidney damage. Am J Kidney Dis 2008;52:595-605.

34. Senichkin VV, Pervushin NV, Zuev AP, et al. Targeting Bcl-2 Family Proteins: What, Where, When? Biochemistry (Mosc) 2020;85:1210-26.

35. Renault TT, Dejean LM, Manon S. A brewing understanding of the regulation of Bax function by Bcl-xL and Bcl-2. Mech Ageing Dev 2017;161:201-10.

36. Zhang M, Zheng J, Nussinov R, et al. Release of Cytochrome C from Bax Pores at the Mitochondrial Membrane. Sci Rep 2017;7:2635.

37. Ansari MY, Ball HC, Wase SJ, et al. Lysosomal dysfunction in osteoarthritis and aged cartilage triggers apoptosis in chondrocytes through BAX mediated release of Cytochrome c. Osteoarthritis Cartilage 2021;29:100-12.

38. Zhao Y, Jing Z, Lv J, et al. Berberine activates caspase-9/ cytochrome c-mediated apoptosis to suppress triplenegative breast cancer cells in vitro and in vivo. Biomed Pharmacother 2017;95:18-24.

39. Yuan C, Pu LQ, He ZL, et al. BNIP3/Bcl-2-mediated apoptosis induced by cyclic tensile stretch in human cartilage endplate-derived stem cells. Exp Ther Med 2018;15:235-41.

40. Conde E, Alegre L, Blanco-Sanchez I, et al. Hypoxia Inducible Factor 1-Alpha (HIF-1 Alpha) Is Induced during Reperfusion after Renal Ischemia and Is Critical for Proximal Tubule Cell Survival. PLoS One 2012;7:e33258.

41. Kaluz S, Kaluzová M, Stanbridge EJ. Regulation of gene expression by hypoxia: integration of the HIF-transduced hypoxic signal at the hypoxia-responsive element. Clin Chim Acta 2008;395:6-13.

42. Jiang Q, Geng X, Warren J, et al. Hypoxia Inducible Factor$1 \alpha(\mathrm{HIF}-1 \alpha)$ Mediates NLRP3 Inflammasome-DependentPyroptotic and Apoptotic Cell Death Following Ischemic Stroke. Neuroscience 2020;448:126-39.

43. Zhang J, Ney PA. Role of BNIP3 and NIX in cell death, autophagy, and mitophagy. Cell Death Differ 2009; 16:939-46.

44. Fu ZJ, Wang ZY, Xu L, et al. HIF-1 alpha-BNIP3mediated mitophagy in tubular cells protects against renal ischemia/reperfusion injury. Redox Biology 2020;36:101671.

45. Gong LJ, Wang XY, Gu WY, et al. Pinocembrin ameliorates intermittent hypoxia-induced neuroinflammation through BNIP3-dependent mitophagy in a murine model of sleep apnea. J Neuroinflammation 2020;17:337.

46. Chen JL, Wang XX, Chen L, et al. A sphingosine kinase 2-mimicking TAT-peptide protects neurons against ischemia-reperfusion injury by activating BNIP3-mediated mitophagy. Neuropharmacology 2020;181:108326.

47. Bellot G, Garcia-Medina R, Gounon P, et al. HypoxiaInduced Autophagy Is Mediated through HypoxiaInducible Factor Induction of BNIP3 and BNIP3L via Their BH3 Domains. Mol Cell Biol 2009;29:2570-81.

(English Language Editor: J. Teoh)

Cite this article as: Yan B, Min SJ, Xu B, Zhang C, Pei J, Zhang W, Luo GH. The protective effects of exogenous spermine on renal ischemia-reperfusion injury in rats. Transl Androl Urol 2021;10(5):2051-2066. doi: 10.21037/tau-21-280 